\title{
The understanding and the implementation of Industry 4.0: An exploratory Study of a Brazilian met- al-mechanic SME
}

\section{O entendimento e a implementação da Indústria 4.0: um estudo exploratório de uma PME metalmecânica brasileira}

\author{
Rafaela Kauane Brizolla ${ }^{\mathrm{a}}$, Tiago Zardin Patias ${ }^{\mathrm{b}}$, Eric Charles Henri Dorion ${ }^{\mathrm{c}}$ \\ a Graduada em Administração.Universidade Federal de Santa Maria, UFSM, Brasil. rafaelabrizolla@hotmail.com \\ b Doutor em Administração. Universidade Federal de Santa Maria, UFSM, Brasil. tzpatias@yahoo.com.br \\ ${ }^{c}$ Doutor em Administração de Empresas. Universidade Federal de Santa Maria (UFSM) - PPGOP, e École de Technologie Su- \\ perieure (ETS), Canadá. echdorion@gmail.com
}

\begin{abstract}
Constant changes are reflecting in all areas and segments of the industry. Innovation and technology are key basis for such transformations. The present work addresses the metal-mechanic "SME's 4.0" challenges and opportunities and study a case of the industry established in the northwest region of the State of Rio Grande do Sul, Brazil. The paper introduces the main concepts, models and pillars of the Industry 4.0, which provided its theoretical background. The research methodological strategy is a case study, since the research clues focus on one specific SME facing the Industry 4.0 reality. The descriptive and qualitative research includes interviews with seven managers of the SME, combined with direct observation and organizational documents. Data were categorized and analyzed using the content analysis technique. The main findings show that the concept of Industry 4.0 is clearly understood within the SME, but it is possible to find that the implementation is still in progress, through the use of the internet of things, robotization and simulation. Challenges that relate to such implementation necessitate a cultural change and an agile adaptation to recurrent innovations, to remain competitive. The opportunities, planning, process innovation and technological updating stand out as the main factors of adaptation. The research shows a need for the upper management to propose a discussion on such topic, in line with the organisation's strategic platform.
\end{abstract}

Keywords: Industry 4.0; Technology; Innovation; Advanced manufacturing; SME.

\section{Resumo}

Mudanças constantes estão refletindo em todas as áreas e segmentos da indústria. Inovação e tecnologia são a base fundamental para essas transformações. O presente trabalho aborda os desafios e oportunidades metalmecânico "PMEs 4.0" e estuda um caso da indústria estabelecida na região noroeste do Estado do Rio Grande do Sul, Brasil. O artigo apresenta os principais conceitos, modelos e pilares da Indústria 4.0, que forneceram sua fundamentação teórica. A estratégia metodológica da pesquisa é um estudo de caso, uma vez que as pistas da pesquisa se concentram em uma PME específica diante da realidade da Indústria 4.0. A pesquisa descritiva e qualitativa inclui entrevistas com sete gerentes da SME, combinadas com observação direta e documentos organizacionais. Os dados foram categorizados e analisados pela técnica de análise de conteúdo. As principais conclusões mostram que o conceito da Indústria 4.0 é claramente entendido dentro das PME, mas é possível descobrir que a implementação ainda está em andamento, através do uso da Internet das Coisas, da robotização e da simulação. Os desafios relacionados a essa implementação exigem uma mudança cultural e uma adaptação ágil às inovações recorrentes, para permanecerem competitivos. As oportunidades, o planejamento, a inovação de processos e a atualização tecnológica destacam-se como os principais fatores de adaptação. A pesquisa mostra a necessidade de a alta gerência propor uma discussão sobre esse tópico, de acordo com a plataforma estratégica da organização.

Palavras-Chave: Indústria 4.0; Tecnologia; Inovação; Manufatura avançada; PME. 


\section{Introduction}

The world is in constant change and evolution. Innovation is increasingly taking place and has been present in people's daily lives, being considered as an essential element for the promotion of development, especially in the industrial area (Jiménez-Jiménez \& Sanz-Valle, 2011). The fourth industrial revolution is a technological transformation that will allow the fusion and the interaction of technologies in different areas of knowledge, such as biological, digital and physical, paving the way to structuring changes beyond systems and machines (Schwab, 2016; CNI, 2018a ; CNI, 2018b).

Technology is already recognized by the organisations as a pillar for greater productivity, speed and process automation and especially competitiveness. The first discussions about the concept of Industry 4.0 happened in Germany in 2011, at the Hannover Messe International, which is considered the largest industrial automation fair in the world (CNI, 2016). Technological innovations are fueling major changes worldwide and bringing to SMEs (Small and Medium Enterprises) benefits and challenges of equal measure. These innovations have significantly boosted business competitiveness by simplifying and adding value to the production processes and products themselves (Damanpour \& Gopalakrishnan, 2001).

The metal-mechanic industry is undergoing a major transformation. The world is moving towards advanced manufacturing, investing in smart factories, in search of automating many processes and improving productivity and competitiveness (Anzola-Román et al., 2018).

The Industry 4.0 is not just a label, or a certification, where it simply implies to an organisation to follow the rules. It builds itself gradually from the organisation's needs where it must suit to a constant transforming reality. It includes various engagements from which projects are built, adjusted and replicated, and it involves complex but small changes, small projects that are aligned and assertive (De Sousa Jabbour et al., 2018). Sharing knowledge becomes especially decisive in shaping a collective future that reflects common values and goals. So, governments, private companies and universities need to form partnerships, seek innovation and competitiveness vis-à-vis other countries to break out of stagnation (Schwab, 2016). Given this scenario, it is important to study the fourth industrial revolution, the history of revolutions, the positioning of the Brazilian metal-mechanic industry and the specific situation of the SME in the context of the Industry 4.0 (FINEP, 2019).

In the Brazilian metal-mechanic industry, according to Portal da Indústria (CNI, 2018), some important initiatives are being implemented. The creation of the SENAI (Serviço Nacional de Aprendizagem Industrial) Innovation Institutes is one of them. Such organisation includes 25 institutes that are already present in 12 Brazilian States, which aim to create agile, innovative and tailored solutions for large and SMEs, to assist them and to perform partnerships within the industry (SENAI, 2018).

Given the importance of the subject for the local SMEs, this case study deals about this industrial environment of constant transformation. It is of great value for the expansion of knowledge in the industrial area and the understanding of the process of technological updating and rapid advance in manufacturing. In this context, this article aims to analyze the case of a metal-mechanic SME located in the northwest region of Rio Grande do Sul, focusing on the Industry 4.0 challenges and opportunities.

\section{Theory}

The theoretical base discusses the rationale about the Industry 4.0, its evolution through its concepts, its benefits and pillars that underlie the theory, pointing out the challenges and impacts of this new industrial trend. 


\subsection{The historic path of the industrial revolutions}

The major industrial revolutions have happened over 300 years, transforming industrial processes and products through technology development (Maynard, 2015). The first industrial revolution, or Industry 1.0, began in the United Kingdom in the late eighteenth century, with the introduction of the mechanical production methods and the application of powered steam energy equipment (Helfat \& Winter, 2011). De Sousa Jabbour et al. (2018) points out that the first industrial revolution was marked by industries that began to use steel as raw material and coal as energy in their manufacturing processes. During this period, between 1780 and 1860 , the steam engine was also perfected, which mechanized tasks performed manually, where the first loom machine and the first mechanical calculator were created. The Industry 2.0 started in the late 19th century and was marked by mass industrial production based on assembly lines. From this revolution, organizational competition started to increase, which supplied the development of industries and competitiveness. It is estimated that during the two decades of the Second Revolution, there was approximately a 67 percent increase in labor in the United States industries. The key contributions of the second revolution were the industrial steel fabrication in practically all industries, like the combustion engine and the invention of the automobile (Belvedere et al., 2013). The third industrial revolution started in the 1960s and was marked by the automation of the production processes, the use of electronics, and the information and telecommunications technology. It is also recognized by the computer revolution, through the development of semiconductors, mainframe computing, personal computing and the internet (National Academy of Science and Engineering, 2013; Maynard, 2015).

The quick widespread of innovation in the Industry 4.0 is astounding. Schwab (2016) reports that initially, the mechanized loom that emerged in the first industrial revolution in Europe took 120 years to spread around. The internet has spread around the world in less than 10 years. The second industrial revolution still needs to be experienced by $17 \%$ of the world's population, as nearly 1.3 billion people do not have access to electricity. The third industrial revolution has reached about 4 billion people, just over half of the world's population, which confirms that these are continuous and nonlinear events.

\subsection{The Industry 4.0}

The world is changing, and the fourth industrial revolution is one of the trends that is accelerating this change and will shape current and future industries. This is the era of digital manufacturing, which has embedded high technology and aims at valuing products and competitiveness in all areas. The Industry 4.0 creates a world where physical and virtual manufacturing systems cooperate globally and flexibly, allowing for full product customization and the creation of new operating models (National Academy of Science and Engineering, 2013; Maynard, 2015).

For the implementation and the experience of the fourth industrial revolution, a change of mindset is essential. It is necessary to be open minded, to be able to have a new perception on the possible technologies that can be implemented, the new processes that can be improved, like agile automation, reduced costs and tighter deadlines; creating value added products, where competitiveness becomes efficient, allowing the organisations to expand their workforce and generate productivity increase (Maynard, 2015; Boston Consulting Group, 2019)

Due to the effectiveness of process automation, investment in advanced manufacturing has been 
increasing and many traditional manufacturing plants are being transformed into intelligent factories (Davis et al., 2012). It is important to note that most of these new technologies are already available, but that the transition into the Industry 4.0 will not happen suddenly, but gradually, where the implementation flow will depend on the economic and strategic factors and the technological capacity of the industry (Hahn Filho, 2016).

Such gradual transformation is possible for any organisations, of all sizes or segments. However, the particular reality of each SME being so, that it is relevant to analyze such adaptation process on a case basis, to expose with clarity the right technologies that implies for an intelligent factory. In this context, Askarany et al. (2012) points out a mix of automation processes and the use of technology that is already installed in the factory with the objective to optimize the process and lower the costs.

\subsection{The Industry 4.0 in Brazil}

Brazil's long-time technological gap has contributed to its low level of competitiveness, but lately the situation has stabilized, compared to other developing countries. Considering that the Brazilian industry needs to compete globally and that it is showing a lower capacity, it must take disruptive actions to change such situation. A new flow of investments, joint with industrial research, will impact directly and increase competitiveness (CNI, 2016).

The Brazilian industry is behind, when compared to developing countries like South Korea and China, in terms of technology development. In fact, Brazil is currently transitioning from the Industry 2.0 toward the Industry 3.0. In Brazil, industries are still replacing the traditional man powered assembly lines by automation through electronics, robotics and programming. But such reality happens at a low pace, below what is necessary to be competitive (Hahn Filho, 2016).

New investments in information and automation technologies must take place in Brazilian SMEs to be recognized as one of the top players among countries with smart factories. The intensive training of managers, engineers and technicians, which is mandatory to work with these technologies, will also guarantee a more qualified workforce (National Academy of Science and Engineering, 2013; Maynard, 2015). As a result, the country may become more competitive and generate performance if long term planning and steps are taken and implemented be the SMEs.

\subsection{The Pillars of the Industry 4.0}

The Industry 4.0 technologies are based on nine pillars that drive the metal-mechanic industry deployment and support (Siemieniuch et al., 2015). The objective is to understand each one of them, in order to support the empirical research.

\subsubsection{Big Data analytics}

In the context of Industry 4.0, the collection and comprehensive assessment of data from many different sources, production equipment and systems, as well as corporate and customer management systems, will become standard to support a prompt decision making. "Applying Big Data to manufacturing will reduce the number of quality assurance workers while increasing the demand for industrial data scientists" (Brown et al., 2011; Gerbert et al., 2015). 


\title{
2.4.2. Autonomous robots
}

Autonomous robots are machines that perform tasks without human intervention and can make decisions, detect and solve problems on the factory floor (CNI Digital, 2017). Some factories have long used robots for complex tasks, but robots are evolving to even greater utility. They are becoming more autonomous, flexible and cooperative. They are able to interact with each other and work safely side by side with humans and learn from them by becoming collaborative. These robots cost less and have a wider range of features than those used in manufacturing today (Royakkers \& van Est, 2015).

\subsubsection{Simulation}

For Confederação Nacional da Indústria Digital (CNI Digital, 2017),

\begin{abstract}
Simulation (or Virtualization) is a virtual reproduction of development, manufacturing environments and processes in factories. It is a practice that enables digital and faithful reproduction of the operation of industrial plants, including equipment, operational and employee functions. In the Industry 4.0, the concept can be applied to every manufacturing plant, making virtual copies of smart factories to better monitor them to predict difficulties and improve production.
\end{abstract}

Such statement implies that simulation improves production results, that it can obtain greater control of processes, and it can identify and minimize failures, contributing to the increase of the work quality of the employees. Simulations will be used more extensively in plant operations to leverage real-time data and mirror the physical world into a virtual model that can include machines, products and humans. This will allow operators to test and optimize machine configurations for the next in-line product in the virtual world before physical switching, thereby reducing machine setup times and increasing quality (Negahban \& Smith, 2014).

\subsubsection{Horizontal and vertical integration systems}

Companies, departments, functions and capabilities will become much more efficient as universal cross-enterprise data integration networks evolve and enable truly automated value chains. Some applications are linked to general urban systems and smart cities, such as solutions for the integration of "smart" vehicles, capable of interacting with each other and exchanging online information about accident or congestion situations. Other applications are environmentally effective by monitoring air quality, beaches, rivers and disaster prediction; building automation allowing the design of intelligent environments (Aquino, 2015; Khaitan \& McCalley, 2015).

\subsubsection{Industrial Internet of Things}

For Almeida (2015), the concept of the industrial Internet of Things (IoT) is:

The Internet of Things (IoT) refers to the integration of physical and virtual objects into networks connected to the Internet, allowing objects to collect, exchange and store data that will be processed and analyzed, generating information and services on a large scale. There are many possibilities of connected objects: cars, smartphones, appliances, clothing, locks, among other devices.

The Internet of Things enables data sharing between devices that control and act in real-time production processes over wireless networks. This will allow field devices to communicate and interact with each other 
and more centralized controllers as needed. It will also decentralize analysis and decision making, enabling real-time responses (Atzori et al, 2010).

\subsubsection{Cyber security}

Cyber security is a set of tools created to protect virtual data. With the integration of systems in the Industry 4.0 , it is essential to secure data against attacks and prevent leaks for any reason. With tangible investments in cyber security, a quick and efficient response to a potential threat is possible (Liao et al., 2017; CNI Digital, 2017). With increased connectivity and the use of industry-standard communication protocols, the need to protect critical industrial systems and manufacturing lines from cyber security threats will increase dramatically. As a result, secure and reliable communications as well as sophisticated machine and user identity and access management will become essential (Dunn-Cavelty, 2010; Warner, 2012).

\subsubsection{Cloud computing}

Cloud computing is "the ability to access and to use services such as storage, databases, network, software and analysis, among others, through the internet" that contributes to the organisations to reduce costs by reducing investments in information technology, such as hardware and infrastructure, staff or commuting (Mell \& Grance, 2011). More production-related ventures will require greater data, by sharing across company sites, systems, and boundaries. As a result, data and machine functionality will increasingly be deployed into the cloud, enabling more data driven services for production systems (Qi et al., 2010; Jothipriya \& Akila, 2016).

\subsubsection{Additive manufacturing}

Companies have begun to adopt additive manufacturing, such as 3D printing, which they use primarily for prototyping and producing individual components. With the rise of the Industry 4.0, these additive manufacturing methods will be widely used to produce small batches of custom products that offer construction advantages such as complex and lightweight designs (Huang et al. 2012). Additive manufacturing, or 3D Printing, is the creation of an object by adding one-to-one ultra-thin layers of materials such as plastic, common steel or titanium alloy, ceramic and sand, among others. 3D printing contributes positively to industries in comparison to traditional manufacturing, since it provides less material waste, simplified logistics and significantly reduced production costs (ASTM, 2010).

\subsubsection{Augmented Reality}

Augmented reality is the technology that allows interaction between virtual and real universes. It is also considered as the overlapping of objects and real images in the virtual environment through a technological device. In the future, companies will be able to make decisions based on cyber representation. Operators will learn to interact with machines, change parameters and retrieve operational data and maintenance instructions. The utilities of such tool are endless (Berryman, 2012). Augmented reality-based systems may support a variety of services, such as selecting parts from an inventory or warehouse, or by submitting repair instructions on mobile devices. These systems are currently in their infancy, but in the future, companies will use much more augmented reality to provide employees with real-time information to improve decision making and work procedures (Akçayir \& Akçayir, 2017). 


\section{Method}

This descriptive case study analysis of a metal-mechanic SME, from the northwestern region of the State of Rio Grande do Sul, Brazil, has the optic of investigating the integration reality of the Industry 4.0. Through an exploratory research, a specific content was sought to conceptualizes how the Industry 4.0 is integrated and evaluated from the actors' points of view, from a theoretical understanding. The secondary data research was conducted through a literature review through scientific articles and theses, reviews, reports and books. Primary data was conducted through interviews, which allowed a structuring construction of ideas and content development. A semi-structured interview script was developed for the application on seven tactical managers, who have relevant contacts with the manufacturing area. Direct observation was also done to supplement the investigation.

A content analysis technique, as proposed by Bardin (2011), was chosen to achieve the research objectives, based on three specific phases: 1) the pre-analysis; 2) the exploration of the material; and 3) the results' treatment, inference and interpretation. In the exploration phase, the material encoding procedure followed the classification and aggregation options. The defined coding form was about classification and aggregation through the choice of categories pattern. In this case four categories of analysis were defined: a) the concept of the Industry 4.0 ; b) the pillars of the Industry 4.0 ; c) the threats from the Industry 4.0; and d) the Industry 4.0 opportunities.

\section{Results analysis}

The analysis follows a path of breaking down the topics into four categories, in order to gain a better understanding of the reality through the concept, pillars, threats and opportunities categories.

\subsection{The concept}

The first question asked was to contextualize what their knowledge about the Industry 4.0 was. For Interviewee "number one", the [...Industry 4.0 marks a global evolution of the whole metal-mechanic industry, where this revolution is specifically a technological evolution, by changing the concept of the relationship between man and machine, and where the macro idea is to combine knowledge, based on data, Big Data. The devices are connected in real time via IoT and the decisions are fast, being made through artificial intelligence, and even have the possibility to access them anywhere through the cloud.... these are some of the industry factors 4.0.].

Interviewee "number three" has commented that the concept would be a paradigm shift from the way factories operate today, which corroborates with Maynard (2015)'s view. The author believes that industries will be considered smarter if they follow a path toward the decentralization of the operations manual control processes, and if they implement control via interconnected smart devices, which encompasses automation and information technology in manufacturing. Such statement is consistent with Interviewee "number four" understanding, which stipulates that the Industry 4.0 will embrace key technological innovations applied in the manufacturing process (Automation, Information Technology, IoT) and will constitute the new production processes; being smarter and more efficient.

The respondents converge with a clear alignment on the understanding of the concepts of the Industry 4.0 , since they demonstrated having knowledge about its origins, its meaning and the impacts it will provide 
to the industry. This knowledge highlights the importance of the subject, even though a recent and not yet explored context is already widespread within the SME.

Regarding the day-to-day learning interface, Interviewee "number one" reveals that he is interested in the subject and performs readings, but as the evolution is constant, every day new innovations show up, new equipment and technology applications in different industry areas appear, making it difficult to be updated and adapted. As he currently works with research and development, he believes it is essential to constantly acquire knowledge about the Industry 4.0 and to develop products aimed at it. Interviewee "number two" states that he believes Brazil is getting worse about implementing innovation, pointing out that Brazil is trying to get out of the second industrial revolution and have to jump straight up to the fourth, or at least try to do it. He thinks it will be a lot of work, due to the lack of focus of the matter. Interviewees "number three" and "number seven" commented that they acquire knowledge from their participations in lectures and courses. Interviewee "number three" believes [...that in the Industry 4.0, there is a huge communication scheme between machines, sensors, collaborative robots, taking part of the hand human work, much of it via software and also, ... there will be broad control over traceability]. Interviewees "number four" and "number six" claim they have little knowledge about the Industry 4.0 and its new technologies, as well as the conceptual pillars that it brings. For Interviewee "number five", the Industry 4.0 will provide automated factories designed to produce large-scale products, eliminating all waste and standard products on a large scale.

The results show eclectic patterns in terms of day-to-day learning interfaces. The knowledge learning patterns that each interviewee adopted are different, showing disruptive interpretations and experiences. The Industry 4.0 learning patterns follow inconsistent day-to-day learning interfaces that are generalist and empirical, showing a lack of theoretical basis on the specific concepts, patterns, actions and practices to be used or implemented in the metal-mechanic industry.

\subsection{The pillars}

One of the questions related to the Industry 4.0 was to identify which pillars they consider most important and why. Interviewee "number one" states that [...all pillars have their particularities, and many aspects are interconnected. It is hard to say which one is more important than the other, since each one has its degree of importance, but Big Data and analysis are considered the basis of knowledge. Without data, no task can be performed since there would be no parameters to make safe decisions.].

According to Interviewee "number four", [... all the pillars cited are important in Industry 4.0, but I realize that Big Data is making a difference with articulated real-time data for fast decision making, standalone robots to increase productivity, to reduce failures and waste. The vertical and horizontal optimized process integration systems, joint with additive manufacturing with 3D printers, enhance multi-project agility capacities, while cloud computing promotes the friendly use of remote access to services anytime and anywhere].

The results show a positive relation between the accumulation of empirical data, or the experience in the manufacturing area, and the capacity of the respondents to identify more opportunities for the pillars' applications. More acquired knowledge lead to a capacity to assume specific steps within the SME toward innovations related to the Industry 4.0. Interviewee "number five" points out that the pillar about the horizontal and vertical integration systems is the most important point, since any factory is process defined, generating more gains in management, changes and process adequacy.

The actions to improve the SME's results can have a very high assertiveness reliability, through rich 
comparative data simulations, or any process that has fast information generation technologies, allowing it more competitiveness in the industry.

The results show information coherence, since each pillar concepts, mixed with the respondents' views, converge on the importance of the industry competitiveness to create an edge over others. The Industry 4.0 pillars form a benchmark platform, which supports the metal-mechanic industry by optimizing its processes. In this context, it is possible to identify some actions that have already been implemented in the SME, on its path to become an organisation of the fourth industrial revolution.

In terms of organizational planning and implementations, eclectic patterns arise among the respondents. According to Interviewee "number two", the company does not yet have a plan or a project about implementing the Industry 4.0 parameters. The SME still does not have an established long-term plan, but it already has installed some new technologies such as the use of robots and some simulations equipment for machinery and cutting. Interviewee "number one" reported new practices that are taking place in the SME since January 2019 that are considered as a disruptive evolution. It started with the database being collected daily and the orders report, as it is considered as the starting point of the data development. Also, other projects such as investments in state-of-the-art equipments may be implemented in the future through IoT and artificial intelligence.

Interviewee "number seven" developed some actions related to online factory operation reporting, robotization in welding processes, machine programming through modern software, customization of the SME's operating system for better programming. The communication and process integration patterns were upgraded, realizing concrete actions that meet the new version of the Industry 4.0.

Figure 1 presents the current situation of the SME on their actions and initiatives about the use of the Industry 4.0 pillars, combined with the opportunities that relate to each pillar.

\begin{tabular}{|c|c|c|}
\hline Big Data and Analytics & $\begin{array}{l}\text { Online manufacturing reporting; } \\
\text { Compilation of data from production } \\
\text { processes. } \\
\text { Real time production progress informa- } \\
\text { tion. } \\
\text { Accurate information. }\end{array}$ & $\begin{array}{l}\text { Automation and report of all SME } \\
\text { processes, as well as support areas. }\end{array}$ \\
\hline Autonomous Robots & $\begin{array}{l}\text { Collaborative welding robots, aligned } \\
\text { with programming that weld perfectly. }\end{array}$ & $\begin{array}{l}\text { Areas with more repetitive work, with } \\
\text { insertion of autonomous robots. } \\
\text { Interaction between robots and } \\
\text { collaborators. } \\
\text { Robot insertion in all welding lines. }\end{array}$ \\
\hline Simulation & $\begin{array}{l}\text { Engineering simulations based on finite } \\
\text { elements. } \\
\text { Equipment design simulation software. } \\
\text { Virtual commissioning. }\end{array}$ & $\begin{array}{l}\text { Factory sensing for layout change } \\
\text { opportunities to make the process faster } \\
\text { and more efficient. }\end{array}$ \\
\hline Augmented Reality & Not yet present in the SME. & $\begin{array}{l}\text { Use of Google Glass in the assembly and } \\
\text { maintenance areas of the SME. } \\
\text { Possibility to send } 360^{\circ} \text { images and/or } \\
\text { videos along with product manuals to } \\
\text { customers. }\end{array}$ \\
\hline Systems integration & $\begin{array}{l}\text { Machining Machines with productivity } \\
\text { identification sensors. } \\
\text { Predictive maintenance. }\end{array}$ & Predictive maintenance in all areas. \\
\hline
\end{tabular}




\begin{tabular}{|c|l|l|}
\hline Additive Manufacturing & Not yet present in the SME. & $\begin{array}{l}\text { 3D printing on final assembly lines. } \\
\text { Addition of materials instead of removal } \\
\text { (machining). } \\
\text { Casting - Obtaining a new part by melting } \\
\text { iron powder. }\end{array}$ \\
\hline Cyber security & $\begin{array}{l}\text { SME's information security and data } \\
\text { through the Information Technology } \\
\text { structure and banks. }\end{array}$ & $\begin{array}{l}\text { To keep all SME connections secure. } \\
\text { Increased security through the Data } \\
\text { Protection Act. }\end{array}$ \\
\hline Cloud & $\begin{array}{l}\text { SME's data saved in more than one cloud } \\
\text { daily, ensuring all data. }\end{array}$ & $\begin{array}{l}\text { RFID (Radio Frequency Identification } \\
\text { Interconnection of manufacturing } \\
\text { processes to streamline and make tasks } \\
\text { more flexible. }\end{array}$ \\
\hline Industrial Internet & $\begin{array}{l}\text { Connection between the PPCP and the } \\
\text { procurement areas to generate a purchase } \\
\text { order when a raw material purchase is } \\
\text { required. }\end{array}$ \\
\hline
\end{tabular}

The analysis The analysis of Figure 1 shows a clear path for the Brazilian metal-mechanic SME on their actions and opportunities, and for the implementation of each topic. According to the Confederação Nacional da Indústria (CNI, 2016) in Brazil, there is a long way to come to a full transformation and acute positioning on recurrent opportunities, but still, almost all the SMEs agree that the Industry 4.0 is an opportunity and not a risk.

\subsection{Opportunities}

The respondents were asked about the industrial prospects and the opportunities and how they view the future of the metal-mechanic industry in such context. It is possible to observe that the increasing development of the industrial activity demonstrates several opportunities and processes improvements, to guarantee greater efficiency and competitiveness and to foster industrial innovation (FINEP, 2019).

Interviewee "number one" and "number two" believe that regarding the metal-mechanic industry, important transformations are happening presently, and it will continue to rise in terms of frequency. Because of the complexity and the depth of the implementations, the recent created culture of innovation will increasingly provoke technology-driven industries to use the collected data, and be connected to the industry from anywhere, allowing the use of equipment that can be autonomous, make decisions, or contain artificial intelligence. Interviewee "number one" believes that the Brazilian metal-mechanic industry has a great potential to be a Industry 4.0 reference in the country, as it holds a culture of pioneering and innovation. But more exact and agile planning is necessary, as the high costs of implementation makes it risky and internally difficult to implement. Interviewee "number two" commented about the fact that the industrial innovation culture needs to start with small projects and promote change gradually, as suggested by CNI (2019). Some national research data aimed to identify the level of maturity of the organisations in implementing the Industry 4.0 showed that less than $50 \%$ of the interviewed companies are just beginning the path of Industry 4.0.

Interviewee "number three" believes the issue will be considered in the future, but unlike Europe, the methods and technologies will take a little longer to arrive in South America. Having few multinationals in Brazil, one may have an increased path of development, but it is not guaranteed. As for the metal-mechanic industry in question, by having partner companies in Europe, it is possible that there is a thought of the "new" and it is perceived that it is possible to increase the efficiency of the factory and this is one of the advantages 
of having these partnerships. But, if it depends only on Brazilian knowledge and investments, the time of application of this method can be extended.

Interviewee "number four" considers the possibility of more automated industries, more machines and fewer labor. Standardized processes will avoid errors, reduce waste, reduce costs and gradually accelerate production (increased productivity). In the future, the SMEs will have to adapt to this new concept because, to survive in the highly competitive market, it is necessary to seek new technologies that ensure permanence in the market, stressing the necessity to innovate.

For the Interviewee "number five", the Industry 4.0 already exists in the SME, through the use of modern machines, the engineering and the equipment of the most advanced software, which already does the planning and programming. He believes that the SME is already on the way of being totally "Industry 4.0". The Interviewee "number six" claims that there is a giant step to achieve innovation and that the SME needs to change its mental model to understand where innovation opportunities lie. From such evidence, it is possible to perceive distinction in the respondents' answers and that there is no alignment in the understanding regarding the SME's situation and its current state of transformation toward the Industry 4.0.

The understanding of Interviewee "number seven" is that the Brazilian metal-mechanic industry has a lot to evolve in order to achieve a full implementation of the Industry 4.0. The automotive industry is advanced towards the newest version of the industry by bringing clearer production standards and settled down. The SME already has internal process phases with automation and sensing aligned with the Industry 4.0. The challenge is to maintain such process chain evolution, by making them to interact with each other intelligently and automatically. Externally, in terms of product, it is necessary to evolve in product engineering, by seeking to deliver to the customer operational technologies and by processing equipment operation information technology.

This positioning corroborates with the view of the President of the Confederação Nacional da Indústria, Paulo Afonso Ferreira, who believes that [...the ability of companies to innovate is crucial to increase the economic and social development of Brazil. Innovation is an unequivocal condition for competition in global markets, the creation of quality jobs and the strengthening of all industries.] (CNI, 2019).

\subsection{Challenges}

In terms of the challenges and the impacts of the implementation of the Industry 4.0, Interviewee "number one" pointed out that there are two key elements to be considered. The first one has a positive impact on the local economy because [...it will create jobs, which today do not yet exist in Brazil.]. It refers to the need to update data and its interpretation, as well as the urgent need to form more qualified people to perform maintenance and equipment procedures. The second one refers to a world-wide trend in the reduction of human labor, due to process automation. This point is problematic and is already discussed by the Nordic countries, where the social consequences of such transformation is being re-evaluated to validate, in other terms, the real need for the full implementation of autonomous industries.

From the point of view of Interviewee "number two", the impact of the Industry 4.0 will provoke the replacement of some repetitive jobs and a new selection patterns for employees in the job market. It will ease the decision processes to be fulfilled and make them more assertive. For business managers, the participation of artificial intelligence in strategic meetings will impact on the discussions, allowing to receive and treat rapidly data and new disruptive information. 
There will be greater competitiveness of job openings, more training, specialization and differentiated attributes, says Interviewee "number five". According to Interviewee "number six", professionals will need to be increasingly qualified for the job market for Brazilian industries to gain in global competitiveness.

Interviewee "number seven" stated that the revolution of the Industry 3.0 already impacted and initiated a transformation in the labor force patterns, where manual labor is increasingly being replaced by machines, and automation has brought the programming of automated resources, which fits with the introduction of the Industry 4.0. The labor market tends to change rapidly mainly in the Industry 4.0 models, but in Brazil, there is still a long way to go in the process, since it is being strongly influenced by social factors that can change the evolution of the labor market.

The use of human intelligence in building and evolving intelligent systems will be increasingly present in our SME, where its main difficulty will be to become an industry from the fourth industrial revolution, having velocity patterns to adapt itself from the losses of the aging of the mechanization, Interviewee "number one" points out that the technology currently involves high costs to make such evolution. He believes that the SME is not focused solely on profits, but on the welfare of its community. From the point of view of Interviewee "number two", our main difficulty can be considered as cultural. Such transformation is not simple and it is essential that all the steps to the success of each project be completed; [...our company has a lot of potential, with competent and engaged people, who basically need some adjustments for a transition that will occur for the better and will be more competitive].

Interviewee "number five" believes that high product diversity and customization limit the capacity to transform the SME into the Industry 4.0, [...since we do not have products and serial production lines]. Interviewee "number six" says [...it is necessary to think outside the box and explore the technologies and innovations that the Industry 4.0 offers]. Such thoughts show a dialectic view of necessity and incapacity, which may resume clearly in a national reality.

As explained by Interviewee "number seven", every decision-making process needs to consider its options, advantages, disadvantages, gains and losses, and its actions to improve its results. It can have a very high assertiveness reliability through simulations, rich in comparative data and every process that have installed and implemented fast information generation technologies, to be much more competitive.

The transition to the Industry 4.0 must be gradual and it must provide the necessary support for such a change. The company needs to trace its path and its well-defined needs, from a strategic alignment within the organisation, to create a culture that is widespread and part of the SME's future path. The company is consolidated and has been in the market for many years, by producing reference equipment. It needs to reposition itself with new challenges such as the Industry 4.0, to remain a competitive company.

\section{Conclusion}

As the world economy is constantly changing with more velocity, and impacting on the Brazilian industrial scenarios, the aim of the study was to investigate the main challenges and opportunities that the Industry 4.0 offers to a Brazilian metal-mechanic SME. The study has given a clout on the understanding and created seeds for future scenarios.

The accomplishment of this study will help managers to focus on knowledge related to the Industry 4.0 as a whole and with an industrial perspective. The business overview with guide the professional and personal development for the managers, providing them accurate and concise knowledge for day-to-day management 
for planning, decision-making and opportunities benchmark improvement. Such study on the SME production and operations management, through a Industry 4.0 perspective, was relevant due to the impact that it has on the flows and processes, through production planning and control, aiming at optimization.

The SME is experiencing a change in production landscape and managing such changes has become an acute challenge. The prospects of the SME, as well as the metal-mechanic industry as a whole, drive trends to adapt as the market is becoming increasingly competitive. To maintain an edge on the competition, the SME must implement innovative decisions.

Since the fourth industrial revolution has emerged and is increasingly present in our daily lives, deepening our knowledge and dedicate it to relevant industry applications opens the door to challenges, innovation opportunities, and pave the way to competitiveness. The results have shown an urgent necessity to normalize the Industry 4.0 all over the metal-mechanic industry and to set up a recurrent path toward learning and knowledge management, showing that it can be much more explored and can generate more of its kind. For future research, it is suggested that a study of the theoretical framework be conducted, since the Industry 4.0 must be analyzed more broadly, in more segments and subdivisions of each SME.

\section{References}

Akçayir, M., \& Akçayir, G. (2017). Advantages and challenges associated with augmented reality for education: A systematic review of the literature. Educational Research Review, 20, 1-11.

Astm. (2010). "Standard Terminology for Additive Manufacturing Technologies. Retrieved from http:// enterprise.astm.org/filtrexx40.cgi? +REDLINE_PAGES/F2792.htm. Accessed on: Jun 2019.

Almeida, H. (2015). Apresentação: Internet das coisas - tudo conectado. Revista da Sociedade Brasileira de Computação, v. 29, n. 4, p. 7-8, 2015.

Anzola-Román, P., Bayona-Sáez, C., \& García-Marco, T. (2018). Organizational innovation, internal R\&D and externally sourced innovation practices: effects on technological innovation outcomes. Journal of Business Research, 91, 233-247.

Aquino, A. (2015). Sensores conectados em rede. Revista da Sociedade Brasileira de Computação, v. 29 , $\mathrm{n}$. 4, p. 9-13.

Askarany, D., Brierley, J. A., \& Yazdifar, H. (2012). The effect of innovation characteristics on activity-based costing adoption. International Journal of Managerial and Financial Accounting, 4(3), 291-313.

Atzori, L., Iera, A., \& Morabito, G. (2010). The internet of things: a survey. Computer Networks, 54(15), 2787-2805.

Bardin, L. (2011). Análise de Conteúdo. 70. ed. São Paulo: São Paulo. 
Belvedere, V., Grando, A., \& Bielli, P. (2013). A quantitative investigation of the role of information and communication technologies in the implementation of a product-service system. International Journal of Production Research, 51(2), 410-426.

Berryman, D. (2012). Augmented Reality: A Review. Medical Reference Services Quarterly. 31(2):212-8.

Boston Consulting Group. (2019). Building Digital Talent and Organization. Retrieved from https://www.bcg. com/en-br/digital-bcg/digital-transformation/building-digital-talent-organization.aspx. Accessed on: 16 Jun. 2019.

Brown, B., Chui, M., \& Manyika, J. (2011). Are You Ready for the Era of Big Data? McKinsey Quarterly (4).

CNI. (2016). Desafios para indústria 4.0 no Brasil: report. Brasília: CNI.

CNIa. (2018). Portal da Indústria. Retrieved from https://noticias.portaldaindustria.com.br/listas/4-mudancasque-as-empresas-podem-implementar-rumo-a-industria-40/\#. Accessed on: 21 jun. 2019.

CNIb. (2018). Portal da Indústria. Retrieved from https://noticias.portaldaindustria.com.br/noticias/politicaindustrial/especialistas-discutem-os-principais-desafios-da-industria-40-para-a-politica-industrial/. Accessed on: 1 dez. 2018.

CNI. (2019). Portal da Indústria. Retrieved from https://noticias.portaldaindustria.com.br/noticias/inovacaoe-tecnologia/impacto-da-tecnologia-no-futuro-sera-debatido-no-8o-congresso-brasileiro-de-inovacao-daindustria/. Accessed on: 12 Jun. 2019.

CNI Digital. (2017). Robôs autônomos. Retrieved from http://www.cnidigital.com.br/artigo/conceitos-robo-sauto-nomos-s-ries-pilares-da-ind-stria-4-0-parte-2-de-9. Accessed on: 01 dez. 2018.

Damanpour, F., \& Gopalakrishnan, S. (2001). The dynamics of the adoption of product and process innovations in organizations. Journal of Management Studies, 38(1), 45-65.

Davis, J.; Edgar, T.; Porter, J., Bernaden, J., \& Sarli, M. (2012). Smart manufacturing, manufacturing intelligence and demand-dynamic performance. Computers and Chemical Engineering, 47, 145-156.

De Guimarães, J. C. F., Severo, E. A., Dorion, E. C. H., Coallier, F., \& Olea, P. M. (2016). The use of organizational resources for product innovation and organizational performance: a survey of the Brazilian furniture industry. International Journal Production Economics. 180, 135-147.

De Sousa Jabbour, A. B. L., Jabbour, C. J. C., Godinho Filho, M., \& Roubaud, D. (2018). Industry 4.0 and the circular economy: a proposed research agenda and original roadmap for sustainable operations. Annals of Operations Research, 1-14. 
Dunn-Cavelty, M. (2010). 'Cyber Security' in A. Collins, Contemporary Security Studies. Oxford: OUP

Finep. (2019). Finep lança ação de fomento a tecnologias da Indústria 4.0 e assina memorando com Israel. FINEP. Retrieved from http://www.finep.gov.br/noticias/todas-noticias/5971-finep-lanca-acao-de-fomento-atecnologias-da-industria-4-0-e-assina-memorando-com-israel. Accessed on: 19 Jun. 2019.

Gerbert, P., Lorenz, M., Rüßmann, M., Waldner, M., Justus, J., Engel, P., \& Harnisch, M. (2015). Industry 4.0: the future of productivity and growth in manufacturing industries. BCG.

Hahn Filho, J. H. (2016). A Era da Internet Industrial e a Indústria 4.0. Produção em Foco, 6(3), 1-3.

Helfat, C. E., \& Winter, S. G. (2011). Untangling dynamic and operational capabilities: strategy for the (N) ever-changing world. Strategic Management Journal, 32(11), 1243-1250.

Huang S., Liu, P., Mokasdar, A., \& Liang, H. (2012). Additive manufacturing and its societal impact: A literature review. International Journal of Advanced Manufacturing Technology 67(5-8) 1-15.

Jiménez-Jiménez, D., \& Sanz-Valle, R. (2011). Innovation, organizational learning, and performance. Journal of Business Research, 64(4), 408-417.

Jothipriya, D., \& Akila, A. (2016). Literature Review: Cloud Computing-Security Issues, Technologies and Challenges, Engineering and Scientific International Journal, 3(2), 1-15.

Khaitan, S. K., \& Mccalley, J. D. (2015). Design techniques and applications of cyberphysical systems: a survey. IEEE Systems Journal, 9(2), 350-365.

Liao, Y., Deschamps, F., Loures, E. F. R., \& Ramos, L. F. P. (2017). Past, present and future of industry 4.0: a systematic literature review and research agenda proposal. International Journal of Production Research, 55(12), 3609-3629.

Maynard, A. D. (2015). Navigating the fourth industrial revolution. Nature Nanotechnology, 10(12), 10051006.

Mell, P., \& Grance T. (2011) “The NIST definition of cloud computing (draft)." NIST special publication 800.145: 7.

National Academy Of Science And Engineering - ACATECH. (2013). Recommendations for implementing the strategic initiative industry 4.0. Final report of the industry 4.0 working group. Frankfurt: ACATECH. Report.

Negahban, A., \& Smith J. S. (2014). Simulation for manufacturing system design and operation: Literature review and analysis. Journal of Manufacturing Systems. 33(2). 241-261. 
Royakkers L., \& Van Est, R. (2015). A Literature Review on New Robotics: Automation from Love to War. International Journal of Social Robotics. 7(5) 549-570.

Schwab, K. (2016). A quarta revolução industrial. São Paulo: Edipro.

Senai. (2018). Relatório de gestão exercício. Retrieved from http://transparencia.pe.senai.br/transparencia/_ lib/arquivos/TCU_28_05_2019_16_43_02.pdf. Accessed on: 12 Jun. 2019.

Siemieniuch, C. E., Sinclair, M. A., \& Henshaw, M. J. C. (2015). Global drivers, sustainable manufacturing and systems ergonomics. Applied Ergonomics, 51, 104-119.

Warner, M. (2012). Cybersecurity: A Pre-history. Intelligence and National Security, 27 (5), 781-799.

Xu, L. D., Xu, E.L., \& Li, L. (2018). Industry 4.0: State-of-the-art and future trends. International Journal of Production Research, 56(8), 1-15.

Qi Z., Cheng L., \& Boutaba, R. (2010). Cloud computing: state-of-the-art and research challenges. Journal of internet services and applications. 1(1) 7-18. 